Editorial

\title{
Transport Policy and Social Inclusion
}

\author{
Miriam Ricci *, Graham Parkhurst and Juliet Jain \\ Centre for Transport and Society, Department of Geography and Environmental Management, University of the West of \\ England, Bristol, BS16 1QY, UK; E-Mails: miriam.ricci@uwe.ac.uk (M.R.), graham.parkhurst@uwe.ac.uk (G.P.), \\ juliet.jain@uwe.ac.uk (J.J.) \\ * Corresponding author
}

Submitted: 6 May 2016 | Published: 7 June 2016

\begin{abstract}
'Transport-related Social inclusion' is a specific naming of the complex set of interrelationships within which accessibility plays an important role in whether a citizen achieves the level of participation in socioeconomic life that he or she seeks. It has its origins in the United Kingdom of the early 2000s, but the diversity of theoretical perspectives, research methods and practical focus shown by the contributions to the present issue on this theme bears witness to the evolution and translation this concept and term has undergone over more than a decade. Nine papers are presented, concerning applications of the concept in three continents, and including some of the poorest and richest per capita income countries on the globe. As well as developing and applying the multi-faceted theories of the processes of exclusion and techniques for the quantitative identification of inclusion, they consider important topics such as the treatment of the less abled and more frail members of society when on the move and the potential for new technological design methods and practical solutions either to enhance inclusion or deepen inequality in our societies. Collectively their conclusions reinforce the message that social exclusion remains multi-dimensional, relational and dynamic, located both in the circumstances of the excluded individual as well as in the processes, institutions and structures that permeate wider society.
\end{abstract}

\section{Keywords}

accessibility; cycling; disabled; gender; mobility; public transport; shared mobility; social exclusion; social inclusion; transport policy

\section{Issue}

This editorial is part of the issue "Transport Policy and Social Inclusion", edited by Miriam Ricci, Graham Parkhurst and Juliet Jain (University of the West of England, UK).

(C) 2016 by the authors; licensee Cogitatio (Lisbon, Portugal). This article is licensed under a Creative Commons Attribution 4.0 International License (CC BY).

\section{Introduction}

'Social inclusion', together with 'social exclusion', was a central concept in transport policy analysis in the wealthy democracies in the 2000s, following the principle that mobility was a key resource enabling participation in society in its broadest sense by providing access to life chances. Those who are deprived of access to life-enhancing opportunities because of transportrelated problems are thus at risk of social exclusion (Jain \& Guiver, 2001; Lucas, 2012; Ricci, 2016). In the UK the link between transport and social exclusion was made explicit with the publication of a comprehensive report by the Social Exclusion Unit (SEU) in 2003, which stated that "problems with transport provision and the location of services can reinforce social exclusion. They prevent people from accessing key local services or activities, such as jobs, learning, healthcare, food shopping or leisure. Problems can vary by type of area (for example urban or rural) and for different groups of people, such as disabled people, older people or families with children." (SEU, 2003, p. 1).

Since the early 2000s the international discourse around social inclusion has seen important develop- 
ments as well as evolution. The United Nations' (UN) 8 Millennium Development Goals to 2015 focussed on poverty, but economic inequality is now integrated within the 17 successor Sustainable Development Goals: a holistic conception of inclusion and participation that is also reflected and supported by several of the papers in this themed issue. Notwithstanding these political developments, however, and some practical progress, the last decade has though been a turbulent one for social equity. Global economic recession from 2008 gave a new lease of life to neoliberal assertions that individual sacrifice is the necessary price of 'purging' the market of inefficiencies, leading to national and international policies of 'inevitable austerity', which in turn spawned a series of street protests around the world, such as 'Occupy'. Protests of this nature and extent had not been seen since 1968. In rejecting Schumpeterian 'creative destruction' as benefiting "the $1 \%$ " they successfully co-opted a mantra in proclaiming 'we are not all in this together'. Whilst the "99\%" also of course represents an enormous range of socioeconomic status, this was perhaps a modern high point in the recognition that an individual's circumstances reflect not only his or her personal qualities and potentials, but also his or her position in interlocked social, economic and environmental systems over which the individual may have little influence, let alone control.

Key to the spontaneous nature of the global protests was a key technological change since the turn of the millennium, and which also has the potential to alter, and in some circumstances positively influence, social inclusion. For example, the proliferation of Information and Communication Technologies (ICTs) such as mobile phones in rural African contexts in which fixedline phones are absent and despite electrical power sources being scarce has been transformative (Porter, 2015). Such developments change the dynamic of accessibility through substituting physical with virtual access to information, goods and services, so travel for utility purposes is less necessary. However, inclusion also needs an element of social and environmental interaction achieved by the richness of 'being there' - copresent with others and experiencing the shared locale first-hand-that positively influences mental and emotional well-being (Cass, Shove, \& Urry, 2005; Parkhurst et al., 2014). However, in many areas of the world, access to education, health care and other essential services remains a challenge, as some of the contributions in this themed issue illustrate.

Translating the recommendations of a growing body of academic research into the implementation of socially-inclusive schemes and processes in practice presents many challenges both in the developed and developing world, and is a powerful reminder of the intrinsic elusiveness of the concept of social inclusion, and how it is measured and benchmarked. Defining so- cial exclusions and implementing solutions is subject to political decision-making and prioritisation. Clearly this is a contested area of inquiry, as Schwanen et al. (2015) posit. Although social inclusion, and exclusion, should be regarded as a process rather than a fixed state, operational understandings often overlook its dynamic, relational and multi-scalar nature, and neglect the inequality gradients in access to material resources, participation and life opportunities evident in the publications in this themed issue.

For this themed issue on Transport Policy and Social Inclusion we sought contributions from a variety of geographical contexts, disciplinary approaches, and research methodologies examining the following key topics:

- The appropriateness and future role of the concept of 'social inclusion' in advancing the theory and practice of transport policy in both affluent and less affluent societies, and for both current and future generations.

- The opportunities and challenges to social inclusion and equity of access associated with the rise of new transport technologies and practices to address sustainability challenges, for example collective or shared mobility schemes.

- The merits and shortcomings of different regulatory contexts of transport decision-making, infrastructure delivery and operations in relation to inclusion in society, participation in decision making processes and the rationale for subsidising transport services.

\section{Overview of the Papers Included in this Themed Issue}

Overall, nine manuscripts are included in this special collection, reporting on research from three different continents and considering a range of modes of travel, digital tools, and the political context. While the majority have a European focus, with four papers addressing transport and social inclusion in UK (Clark \& Curl, 2016; Marshall et al., 2016; Pooley, 2016; Velho, Holloway, Symonds, \& Balmer, 2016), one in Sweden (Lättman, Friman, \& Olsson, 2016) and one in France (Purwanto, 2016), three explore different elements of the African (Alando \& Scheiner, 2016; Kett \& Deluca, 2016) and Asian (Thynell, 2016) contexts.

From a methodological perspective, the papers present a variety of approaches (qualitative, quantitative, mixed methods and a computer software simulation) drawn from a wide range of disciplinary areas, including sociology, history, gender and development studies, economics, science and technology studies, accessibility planning, engineering and transport studies. This demonstrates the extent to which the topic of transport policy and social inclusion lends itself to, and clearly benefits from, a cross-disciplinary examination. 
The papers engage with a variety of transport users providing useful insights into the experiences of interest groups such as women (Thynell, 2016), disabled children (Kett \& Deluca, 2016) and wheel-chair users (Velho et al., 2016).

Marshall et al. (2016) present a software design tool named HADRIAN, which can evaluate designs (e.g. of buses and their associated infrastructure) for their qualities of physical accessibility, through the use of a virtual user group developed as the embodiment of over a hundred people. The paper highlights the issues encountered by standing passengers, of different ages and with varying levels of dexterity and physical ability, when trying to 'hold on' inside a standard UK bus whilst traversing the moving vehicle to get a seat. The experiences of the virtual users are further explored through correlation with data from the Disability Follow-up Survey of Great Britain, which allowed the authors to estimate the potential exclusion of certain individuals due to poor public transport design.

The accessibility of British public transport, i.e. London buses, is also the focus of the mixed-method research study reported by Velho et al. (2016). The authors contend that, despite improvements to the design of London buses, wheelchair users still encounter accessibility barriers. They combine objectively measured biomechanical data and subjectively reported user-experience to identify the physical challenges associated with propelling a wheelchair up ramps to access the bus. In addition to these barriers, participants reported anxiety and social isolation as consequences of sub-optimal public transport infrastructure design.

Still on the bus, Lättman et al. (2016) contribute to the debate around transport and social inclusion by exploring the concept of perceived accessibility using a quantitative survey of 705 Swedish bus passengers. In their study, perceived accessibility refers to the extent to which participants find it easy to lead a satisfactory and socially inclusive life by using the bus as a means of transport. Perception of quality, in particular concerning reliability/functionality of travel and courtesy/simplicity during the journey, was found to be a key determinant of perceived accessibility, captured through the Perceived Accessibility Scale. Moreover, safety was found to have both a direct and an indirect mediating effect on the overall perceived accessibility scores. An advantage of this methodology, the authors claim, is the possibility to capture the distinctive perceptions of different age and/or social groups living in the same areas and using the same bus services, which would not be possible with traditional methods using objective measurements of accessibility. These findings are a reminder that the subjective experience should be as important as objective indicators when planning for a socially inclusive transport system.

Moving on to other transport modes, two papers in this special collection examine the role of cycle-based transport in providing access to life opportunities. Both of these papers are based on research studies conducted in sub-Saharan Africa, where non-motorised transport is prevalent and absolute poverty is widespread. Alando and Scheiner (2016) report that, in these countries, the most vulnerable women, children, older and disabled people are often prevented from making journeys because of poor road conditions, unaffordability, lack of private transport, and poor and/or unreliable public transport. This is a major cause of social exclusion. In their analysis of transport policy (the Integrated National Transport Plan) and economic development strategy (Kenya Vision 2030) in the context of the city of Kisumu in Kenya, the authors find that major transport infrastructure projects aimed at improving safety, connectivity and accessibility have created street-spaces that exclude cycling, with negative implications for the poor majority who rely precisely on cycle-based mobility, e.g. bike taxi services, to access life chances. They discover that, although both economic and transport strategies have the potential to make the streets of Kimusu more cycle-friendly and inclusive, there are crucial elements of discordance that need addressing. Their study recommends that the policy documents should be harmonised, take social inclusion as a goal in itself rather than a means to participation in the economy, and recognise cycling as a right to be protected by the state.

The second of these two papers focuses on providing accessible transport to school for children with disabilities in Zimbabwe (Kett \& Deluca, 2016). The authors report on a participatory, community-led project that helped a number of schools in Mashonaland West Province to identify, procure and operate a bespoke transport service for school children with disabilities: trailers pulled by tricycles, produced locally and affordable for the communities involved. This contribution sheds light on the links between access to education, transport and children with disabilities in the context of a developing economy in the Global South, which is key to expand the literature that so far has predominantly been concerned with more affluent societies in the Global North. Perhaps unsurprisingly, their findings on the community-led transport intervention point to additional barriers faced by disabled children in Zimbabwe, beyond the realm of transport, that would require a more systematic and radical societal transformation. However, the authors argue that localised measures such as the ones developed for the project could make education more inclusive in conjunction with additional life skills training for the children, training for the drivers, improvements to local roads and their continued maintenance.

Remaining in a non-Western context but focusing her inquiry on mobility and gender, Thynell (2016) develops a critique of the policies of some of the most influential global economic and political actors, namely 
the World Bank, other major development banks and the UN, using the lens of development and gender studies. In doing so, she reaffirms the constraints faced by women in rapidly growing Asian cities such as New Delhi, Mumbai, Jakarta and many others. Women disproportionately lack private motorised means of transport, heavily rely on walking and/or cycling and, if they can afford it, use formal and informal public transport, which is often in a poor condition, unsafe and unreliable. Although inclusive and equitable mobility is indeed a goal for the UN and other major international actors, Thynell argues that this has not fundamentally improved the conditions for women as transport users and the quest for gender equality in the mobility arena is still ongoing. She recommends the use of feminist epistemology and development research as key disciplinary perspectives offering effective methods to study and understand the social structures as well as the geographical, cultural and economic factors that shape transport systems in growing Asian cities.

Shared mobility, such as car sharing (in the UK 'car clubs') and bike sharing, has become a growing area of interest among academic scholars and features in one of the papers included in this collection. Focusing on the car and bike sharing provision in Glasgow, Scotland (UK), Clark and Curl (2016) address the question of whether and to what extent these schemes are socially inclusive. To achieve this, they consider bike-sharing stations and car club parking bays as 'destinations', and use accessibility planning and equality impact assessment. The findings suggest that shared mobility is only available to $10-15$ percent of the resident population and that the market imperative might prevent its diffusion to areas of the city most at risk of social exclusion. These results highlight the continuing tension between supporting the economic sustainability of shared mobility business models on the one hand, and reducing inequalities in access to shared transport options on the other.

In a contrasting approach to the other papers, although with interesting parallels with the transport conditions in some developing country contexts today, Pooley (2016) adopts a historical perspective to look at how people accessed everyday transport in the UK over the past two centuries, using evidence drawn from life writing and oral testimonies. He argues, in line with other scholars in the field of mobilities, that currently, at least in the most industrially developed societies, there is an expectation that travel over long and short distances should be unrestricted. In the past, travel options were fewer and most of the population in the UK travelled in much the same way. The oral and written evidence provided shows that people from different backgrounds and social status had to make relatively uncomfortable and long journeys in order to engage in their day-to-day activities, judged from our current modern standards, but this didn't prevent them from engaging in such activities. In other words, Pooley suggests, expectations in the past were lower and travel experiences more uniform across much of the population, so much so that in the past social inclusion might have been perceived to be greater than it is today.

Likewise the final paper adds a different dimension. Purwanto (2016) uses an econometric methodology, namely the method of concentration index decomposition, to examine the link between income inequality and mobility inequality by analysing French survey data at several points in time over the last two decades of the twentieth century, characterised by a rise in social and economic inequalities. His research demonstrates that understanding both the static and dynamic relationships between different indicators of socioeconomic inequality on one side, and mobility inequality on the other, is indeed a very complex subject, as mobility can be regarded both as a dependent and as an independent variable in relation to income. Considering the relationship at one specific point in time, inequality in the distribution of per capita income and per capita car ownership are the two main factors explaining observed mobility inequality. Dynamically, the evolution of the inequality indexes of these two factors contributed to reducing mobility inequalities between 1983 and 1997. Purwanto concludes that the key concept is the evolution of the elasticity between mobility and income and recommends that transport policies aim at reducing the effects of such elasticity.

\section{Conclusions}

The diversity of contributions to the present themed issue confirms that the concept of Social Inclusion applied to transport and mobility problems continues to have relevance within the industrialised democracies within which it emerged but that is has also been adapted to offer explanatory power and practical purpose across a wider range of global social contexts. The concept also survives through ongoing socioeconomic transition, including economic recession as one reason why the social inclusion debate shifts in and out of favour in different political arenas, and technological transition, notably the proliferation of ICTs, which requires the consideration of inclusion as not limited to physical participation.

Yet, as articulated by methodical analysis by a number of the papers, transport-related social exclusion continues to be identified in new configurations, although many different initiatives are being implemented and evaluated for effectiveness. Here, the themed issue contributes in providing for relevant knowledge exchange from the Global South to the Global North, as well as vice versa.

However, despite local successes, by no means is all political development currently oriented towards re- 
ducing exclusion, and overall the conclusions of the contributing authors are a helpful reminder that transport-related social exclusion is indeed multidimensional, relational and dynamic, for example, located both in the circumstances of the disabled child who faces barriers to accessing education, as well as in the processes, institutions and structures that permeate wider society.

\section{Acknowledgements}

We are grateful to all the authors that submitted a manuscript for this themed issue and to the peerreviewers for their helpful feedback.

\section{Conflict of Interests}

The authors declare no conflicts of interest.

\section{References}

Alando, W., \& Scheiner, J. (2016). Framing social inclusion as a benchmark for cycling-inclusive transport policy in Kisumu, Kenya. Social Inclusion, 4(3), 46-60.

Cass, N., Shove, E., \& Urry, J. (2005). Social exclusion, mobility and access. The Sociological Review, 53(3), 39-555.

Clark, J., \& Curl, A. (2016). Bicycle and car share schemes as inclusive modes of travel? A socio-spatial analysis in Glasgow, UK. Social Inclusion, 4(3), 83-99.

Jain, J., \& Guiver, J. (2001). Turning the car inside out: Transport, equity and environment. Social Policy and Administration, 35(5), 69-586.

Kett, M., \& Deluca, M., (2016). Transport and access to education in Mashonaland West Province, Zimbabwe. Social Inclusion, 4(3), 61-71.

Lättman, K., Friman, M., \& Olsson, L. E. (2016). Perceived accessibility of public transport as a potential indicator of social inclusion. Social Inclusion, 4(3), 36-45.

Lucas, K. (2012). Transport and social exclusion: Where are we now? Transport Policy, 20, 105-113.
Marshall, A., Summerskill, S., Case, K., Hussain, A., Gyi, D., Sims, R., . . . Barnes, J. (2016). Supporting a design-driven approach to social inclusion and accessibility in transport. Social Inclusion, 4(3), 7-23.

Parkhurst, G., Galvin, K., Musselwhite, C., Phillips, J., Shergold, I., \& Todres, L. (2014). Beyond transport: Understanding the role of mobilities in connecting rural elders in civic society. In C. Hennesey, R. Means, V. Burholt (Eds.), Countryside connections: Older people, community and place in rural Britain (pp. 125-157). Bristol: Policy Press.

Pooley, C. (2016). Mobility, transport and social inclusion: Lessons from history. Social Inclusion, 4(3), 100109.

Porter, G. (2015). Mobile phones, mobility practices, and transport organization in sub-Saharan Africa. Mobility in History, 6(1), 81-88.

Purwanto, J. (2016). Does a rise in income inequality lead to rises in transportation inequality and mobility practice inequality? Social Inclusion, 4(3), 110-132.

Ricci, M. (2016) Young age, mobility and social inclusion in a disadvantaged urban periphery in England. In L. Murray, \& S. Robertson (Eds.), Intergenerational mobilities: Relationality, age and the lifecourse. Oxford: Routledge.

Social Exclusion Unit. (2003). Making the connections: Final report on transport and social exclusion, London: Social Exclusion Unit.

Schwanen, T., Lucas, K., Akyelken, N., Solsona, D. C., Carrasco, J. A., \& Neutens, T. (2015). Rethinking the links between social exclusion and transport disadvantage through the lens of social capital. Transportation Research Part A: Policy and Practice, 74, 23-135.

Thynell, M. (2016). The quest for gender-sensitive and inclusive transport policies in growing Asian cities. Social Inclusion, 4(3), 72-82.

Velho, R., Holloway, C., Symonds, A., \& Balmer, B. (2016). The effect of transport accessibility on the social inclusion of wheelchair users-A mixed method analysis. Social Inclusion, 4(3), 24-35.

\section{About the Authors}

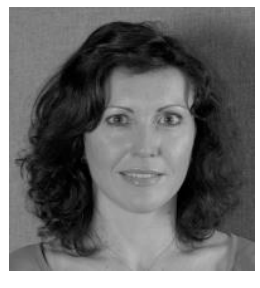

Miriam Ricci is a Senior Research Fellow at the Centre for Transport \& Society at the University of the West of England, Bristol (UK). Her key research interest is sustainable and equitable mobility. She has extensive expertise in applied social research and is involved in several projects on transport policy evaluation, innovative vehicle technologies and shared mobility. Miriam's academic background is multi-disciplinary, with an MSc in Physics and a Ph.D. in Innovation Studies. Some of her past research explored risk perception and public engagement with hydrogen. Before pursuing an academic career, Miriam worked in the private and public sector in Italy, Luxembourg and the UK. 


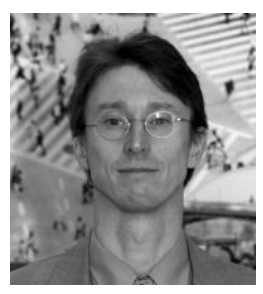

Graham Parkhurst is Professor of Sustainable Mobility and Director of the Centre for Transport \& Society at the University of the West of England, Bristol (UK). Graham has researched and taught in the field of transport and mobility studies since 1991. A key driver of his scholarship has been to understand who benefits and who loses from transport policy change and new transport facilities. His research relating to social inclusion has included examinations of behavioural responses to a new light railway in Sheffield (UK), the interaction between transport and air quality policies, the mobility of poor citizens in Ahmedabad (India), the provision of 'public transport' facilities dedicated to motorists and the mobility and wellbeing of the ageing population of rural areas in Southwest England and Wales.

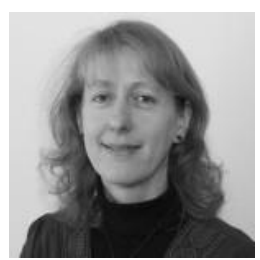

Juliet Jain has a background in the social sciences and is a Senior Research Fellow at the Centre for Transport \& Society at the University of the West of England, Bristol (UK). The impact of transport systems of equality underpins her interest in everyday mobilities and digital technology, and specifically in considering alternatives to the car and on women's mobility. 